\title{
Study on Energy Efficient Operation of Air-Conditioning Cooling Water System
}

\author{
Wang Liang ${ }^{1, *}$, Yang Lu-lu ${ }^{2}$ and Tian Ya-bin ${ }^{1}$ \\ ${ }^{I}$ School of Civil Engineering and Architecture, Southwest University of Science and Technology, Mianyang 621010, \\ China \\ ${ }^{2}$ Key Laboratory of the Three Gorges Reservoir Region's Eco-Environment, Ministry of Education, Chongqing universi- \\ ty, Chongqing 400045, China
}

\begin{abstract}
The control logic of frequency adjustment for pump and cooling tower fan has been presented in this paper, based on the operation mode of a chiller with one pump and one cooling tower. Optimum outlet water temperature control of cooing tower has been put forward through analysis and comparison among factors influencing it, based on measured data. A mathematical model of energy consumption has been established under different outdoor wet-bulb temperature and load rate conditions. The optimized controlling strategy has been obtained after the analysis on energy consumption under two different operational strategies with different number of cooling towers in service. In partial load condition, the best operation mode of cooling water system is the optimal water outlet temperature control system, which aims at the lowest comprehensive system energy consumption. Cooling water system can match the best temperature difference and determine the fan frequency according to optimum outlet temperature automatically. Variable frequency control should be applied to fans; meanwhile, routing maintenance and cleaning is also needed for an even distribution of water and effective use of heat exchange area.
\end{abstract}

Keywords: Cooling water, cooling tower, energy efficiency, optimized operation

\section{INTRODUCTION}

There are several options for operation mode for airconditioning cooling water system under partial load rate [12]. It is beneficial for chiller's performance when the temperature for the water outlet for the cooling tower is lowered (hereafter refer to as $t_{\text {out }}$ ), however this results in a rise in the energy consumption of cooling tower fan and pump. The cooling ability of cooling tower is also influenced by the outdoor wet-bulb temperature [3] (hereafter refer to as $t_{s}$ ). As a result, there exists an energy consumption coupling problem among chillers, pump and cooling tower in cooling water system. Energy conservation potential for variable flow system can be put to effect and be used widely only, when reasonable design and high control performance as well as effective management are available. As evaporator load and $t_{s}$ are variables which cannot be artificially controlled in realtime, combination control for pump and cooling tower according to the change of external conditions is needed in order for efficient control.

Thielma put forward the optimization methods for operation and management of inlet cooling water temperature in

\footnotetext{
*Address correspondence to this author at the Southwest University of Science and Technology, Mianyang, China. Postcard: School of Civil Engineering and Architecture, Southwest University of Science and Technology, Mianyang 621010, China; Tel: 13990167483;

E-mail: wangliangmy83@163.com
}

1983 [4], however, the relationship among energy consumption of chiller, the cooling water temperature and the flow rate of cooling water had not been discussed from the system's point of view in early researches. In 1990, Olson used hybrid integrated nonlinear problem method to study system optimization control when several chillers and cooling towers were in serviced simultaneously, and an empirical energy consumption model for chiller and cooling tower fan had been obtained [5]. Based on the performance analysis of the chillers and cooling towers under different conditions of water flow rate, water temperature, and outside climate, Austin optimized the operational conditions for temperature and flow rate of cooling water and operation number of cooling tower and chiller in 1993 [6]. Yao established the empirical model for chiller, pump and cooling tower, and designed the optimal control for cold source of air-conditioning system when coefficient of system performance was taken as the objective function [7].

Many researchers have studied the model for cooling tower of cooling water system [8-13]. It has been the basis for majority of the modern cooling tower analyses. A revised model was adopted by a software package for energy calculation. However, the Merkel method does not accurately represent the physics of heat and mass transfer process in the cooling tower fill [14]. HVAC Toolkit developed the equations necessary to apply on the effectiveness-NTU method directly, to counterflow cooling towers [15]. The mutual impact of energy consumption among chiller, pump and 
Table 1. Equipment technical parameters of cooling water system.

\begin{tabular}{|c|c|c|}
\hline Equipment & Technical Parameter & Value \\
\hline \hline Pump & $700 \mathrm{~m}^{3} / \mathrm{h}, 32 \mathrm{~m}, 75 \mathrm{~kW}$ & Four \\
\hline Pump & $350 \mathrm{~m}^{3} / \mathrm{h}, 32 \mathrm{~m}, 55 \mathrm{~kW}$ & Two \\
\hline Cooling tower & $700 \mathrm{~m}^{3} / \mathrm{h}, 22 \mathrm{~kW}$ & Three \\
\hline Cooling tower & $350 \mathrm{~m}^{3} / \mathrm{h}, 11 \mathrm{~kW}$ & One \\
\hline
\end{tabular}

Table 2. Linear regression factor.

\begin{tabular}{|c|c|c|c|}
\hline Types of Variable & Factor & Range & Unit \\
\hline \hline \multirow{2}{*}{ Dependent variable } & $\mathrm{t}_{\text {out }}$ & $27 \sim 32.9$ & ${ }^{\circ} \mathrm{C}$ \\
\hline \multirow{3}{*}{ Independent variable } & $\mathrm{t}_{\text {in }}$ & $27.7 \sim 39$ & ${ }^{\circ} \mathrm{C}$ \\
\cline { 2 - 4 } & $\mathrm{Q}_{\text {in }}$ & $225 \sim 712$ & $\mathrm{~m}^{3} / \mathrm{h}$ \\
\cline { 2 - 4 } & $\mathrm{G}_{\text {in }}$ & $73.6 \sim 122.76$ & $\mathrm{~kg} / \mathrm{s}$ \\
\cline { 2 - 4 } & $\mathrm{t}_{\mathrm{s}}$ & $24.4 \sim 27.4$ & ${ }^{\circ} \mathrm{C}$ \\
\hline
\end{tabular}

Table 3. Correlation coefficient.

\begin{tabular}{|c|c|c|c|c|}
\hline Model & $\begin{array}{c}\text { Unstandardized Coefficient } \\
\text { B }\end{array}$ & Standard Deviation & T check Value & $\mathbf{P}$ \\
\hline Constant & 0.331 & 1.665 & 0.199 & 0.843 \\
\hline $\mathrm{t}_{\mathrm{in}}$ & 0.552 & 0.077 & 13.197 & 0.000 \\
\hline $\mathrm{Q}_{\text {in }}$ & 0.001 & 0.042 & 3.243 & 0.000 \\
\hline $\mathrm{G}_{\text {in }}$ & -0.013 & 0.000 & -3.307 & 0.001 \\
\hline$t_{s}$ & 0.483 & 0.004 & 6.262 & 0.001 \\
\hline
\end{tabular}

cooling tower needs to be studied in order to obtain an optimized operation of air-conditioning system.

The control logic of frequency adjustment for pump and cooling tower fan is presented in this paper based on the operation mode of a chiller with one pump and one cooling tower. Through comparative analysis on energy consumption of water system under different external conditions the optimized control strategy has been obtained after using different operational strategies and running different numbers of towers.

\section{CORRELATION ANAYSIS OF INFLUENCING FACTORS}

\subsection{Project Introduction}

Three $2637 \mathrm{~kW}$ centrifugal chillers and one $1044 \mathrm{~kW}$ screw chiller have been chosen for the air-conditioning system of an educational building in Chongqing, while there were six cooling pumps and four cooling towers working for the system. The equipment's technical parameters are as shown in Table 1.

\subsection{Correlation Analysis of Influencing Factors}

Four variables influencing outlets of water temperature are as follows: Inlet water temperature (hereafter referred to as $t_{\text {in }}$ ) and flow (hereafter referred to as $Q_{\text {in }}$ ) of cooling tower, outdoor wet-bulb temperature (hereafter referred to as $t_{s}$ ) and inlet air flow of cooling tower (hereafter referred to as $G_{i n}$ ). Conditions of Linear regression for these four factors as independent variables are shown in Table 2.

Conclusion has been obtained as shown in Tables $\mathbf{3}$ and $\mathbf{4}$ by the use of a statistical software SPSS for analyzing input data.

A multiple linear regression equation could be obtained through statistical analysis from above: 
Table 4. Factor correlativity.

\begin{tabular}{|c|c|c|c|c|}
\hline Measured $\mathbf{t}_{\text {out }}$ & $\mathbf{t}_{\mathbf{s}}$ & $\mathbf{t}_{\text {in }}$ & $\mathbf{Q}_{\text {in }}$ & $\mathbf{G}_{\text {in }}$ \\
\hline \hline 1.000 & 0.629 & 0.757 & 0.310 & 0.121 \\
\hline
\end{tabular}

Table 5. Different controlling mode of cooling water system.

\begin{tabular}{|l|c|}
\hline No. & Different Controlling Method \\
\hline \hline & To obtain optimum $\mathrm{t}_{\text {out }}$ when difference between $\mathrm{t}_{\text {in }}$ and $\mathrm{t}_{\text {out }}$ at $6^{\circ} \mathrm{C}$ \\
\hline & To obtain optimum $\mathrm{t}_{\text {out }}$ when difference between $\mathrm{t}_{\text {in }}$ and $\mathrm{t}_{\text {out }}$ at $5^{\circ} \mathrm{C}$ \\
\hline & To obtain optimum $\mathrm{t}_{\text {out }}$ when difference between $\mathrm{t}_{\text {in }}$ and $\mathrm{t}_{\text {out }}$ at $4^{\circ} \mathrm{C}$ \\
\hline & To obtain optimum $\mathrm{t}_{\text {out }}$ when difference between $\mathrm{t}_{\text {in }}$ and $\mathrm{t}_{\text {out }}$ at $3^{\circ} \mathrm{C}$ \\
\hline & $\mathrm{t}_{\text {out }} 3^{\circ} \mathrm{C}^{\circ}$ higher than outdoor wet-bulb while difference between $\mathrm{t}_{\text {in }}$ and $\mathrm{t}_{\text {out }}$ at $5^{\circ} \mathrm{C}$ \\
\hline & Operation control at rated condition of cooling pump and tower \\
\hline
\end{tabular}

$t_{\mathrm{out}}=0.331+0.43 t_{s}+0.552 t_{i n}+0.001 Q_{i n}-0.013 G_{i n}+\varepsilon\left(\mathrm{R}^{2}=\right.$ $0.841)(1)$

It can be seen that $t_{\text {in }}$ is the key factor impacting $t_{\text {out }}$ while $t_{s}$ is the secondary factor. Therefore, the order of the four factors is $t_{\text {in }}>t_{s}>Q_{\text {in }}>G_{i n}$.

\section{CONTROL STRATEGY}

\subsection{Control Strategy for Optimum $t_{\text {out }}$}

Cooling tower is controlled by optimum $\mathrm{t}_{\text {out }}$ while cooling pump is controlled by constant difference $\left(5^{\circ} \mathrm{C}\right.$ or $\left.4^{\circ} \mathrm{C}\right)$ between $t_{\text {in }}$ and $t_{\text {out }}$. In order to minimize the total energy consumption of the cooling water system through frequency control on pump and cooling tower fan under constant $t_{\text {out }}$, the controlling principle is as follows:

1) When outlet chilled water is at $6^{\circ} \mathrm{C}$ and the chilled water flow changes with load of evaporator, the mathematical relationship among $t_{\text {out }}, Q_{\text {in }}$ and EER of chiller is then established under different load rates. 2) After statistical model of $t_{\text {out }}$ being determined, mathematical relationship among $t_{\text {out }}$, $t_{s}, Q_{\text {in }}, t_{\text {in }}$ and $G_{\text {in }}$ is obtained. 3) The Energy consumption model for pump, cooling tower and chiller has been established. 4) To establish functional relation between $t_{\text {out }}$ and total energy consumption of pump, cooling tower and chiller by using optimum calculation method of MATLAB. 5) To minimize the energy consumption of the system through optimum, $\mathrm{t}_{\mathrm{out}}$ is derived from the established function relation by using constrained nonlinear unary optimization method.

\subsection{Parameter Determination}

Lower limit of inlet water temperature of condenser is $19^{\circ} \mathrm{C}$ while its upper limit is $33^{\circ} \mathrm{C}$. Allowable water flow range of condenser is $401 \sim 702 \mathrm{~m}^{3} / \mathrm{h}$ because the lowest frequency of pump is $30 \mathrm{~Hz}$. Allowable flow range of cooling tower fan is $73.6 \sim 122.76 \mathrm{~kg} / \mathrm{s}$ because the lowest frequency is $30 \mathrm{~Hz}$.

\section{COMPARISON OF ENERGY CONSUMPTION}

\subsection{Controlling Method of Cooling Water System}

No. (1) (4) in Table 5 are optimum controlling mode for outlet water while No. (5) is the traditional one when $\mathrm{t}_{\text {out }}$ is constant (higher than outdoor wet-bulb by $3^{\circ} \mathrm{C}$ ). In order to find the optimum control strategy at different external conditions when one pump with a cooling tower, is compared with different control methods and rated condition No. (6) is conducted.

\subsection{Comparison on Energy Consumption Among Differ- ent Controlling Mode}

Relationships between energy consumption and $t_{\mathrm{s}}$ under different load rate are as shown in Fig. (1-5) through the calculation of energy consumption at different controlling mode.

It can be shown from the figures that under $100 \%$ load rate, energy consumption in mode (2), is the lowest. Compared with mode (6) the energy efficient rate reaches at $4.3 \%$ as $\mathrm{t}_{\mathrm{s}}$ decreased by $0.5^{\circ} \mathrm{C}$ from $27^{\circ} \mathrm{C}$ to $25^{\circ} \mathrm{C}$.

Under $90 \% \sim 70 \%$, energy consumption in mode (3) is the lowest load rate. Compared with mode (6) the energy efficient rate reaches at $3 \% \sim 4.9 \%$ as $\mathrm{t}_{\mathrm{s}}$ decreased by $0.5^{\circ} \mathrm{C}$ from $27^{\circ} \mathrm{C}$ to $25^{\circ} \mathrm{C}$. Under $60 \%$ load rate, energy consumption in mode (4) is the lowest. Compared with mode (6) the energy efficient rate reaches at $6.1 \%$ as outdoor wet-bulb temperature decreased by $0.5^{\circ} \mathrm{C}$ from $27^{\circ} \mathrm{C}$ to $25^{\circ} \mathrm{C}$. 


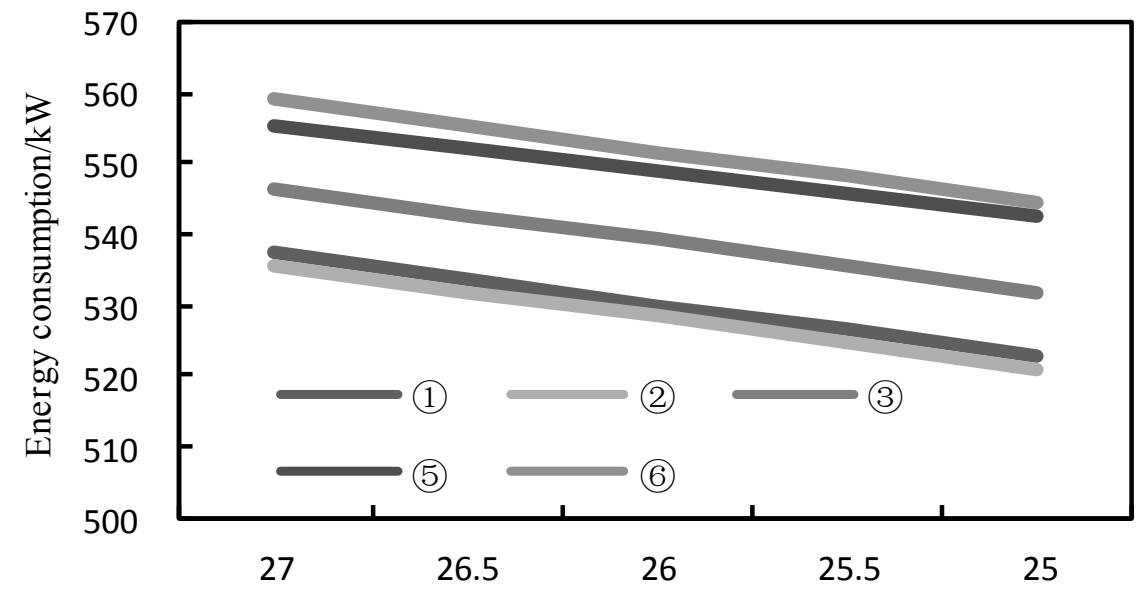

Outdoor wet bulb temperature $/{ }^{\circ} \mathrm{C}$

Fig. (1). Energy consumption of different controlling mode under 100\% load rate.

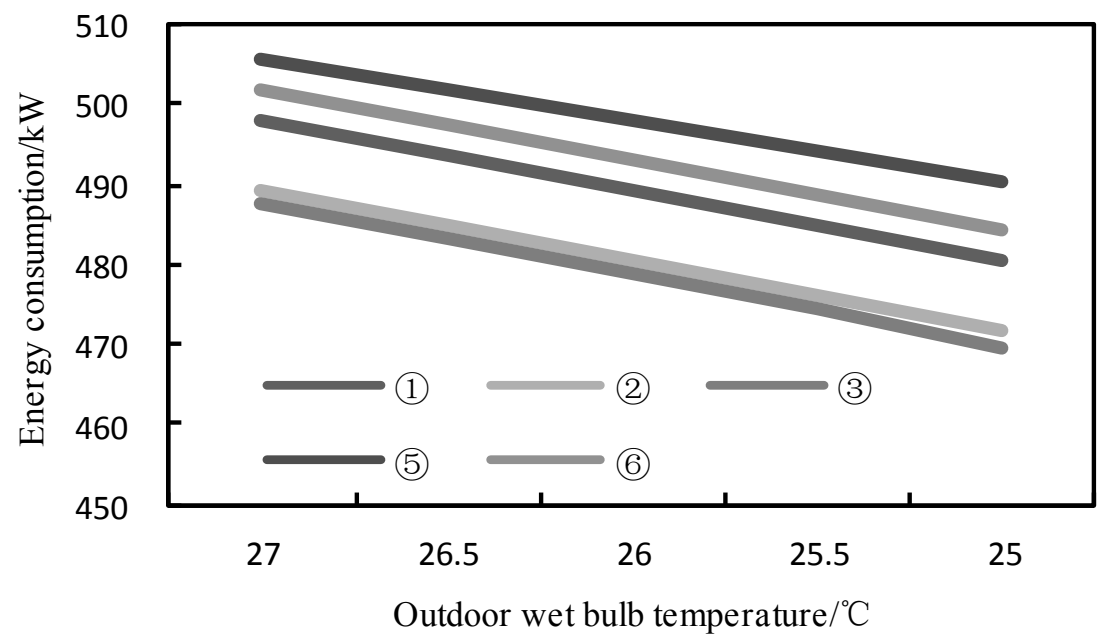

Fig. (2). Energy consumption of different controlling mode under $90 \%$ load rate.

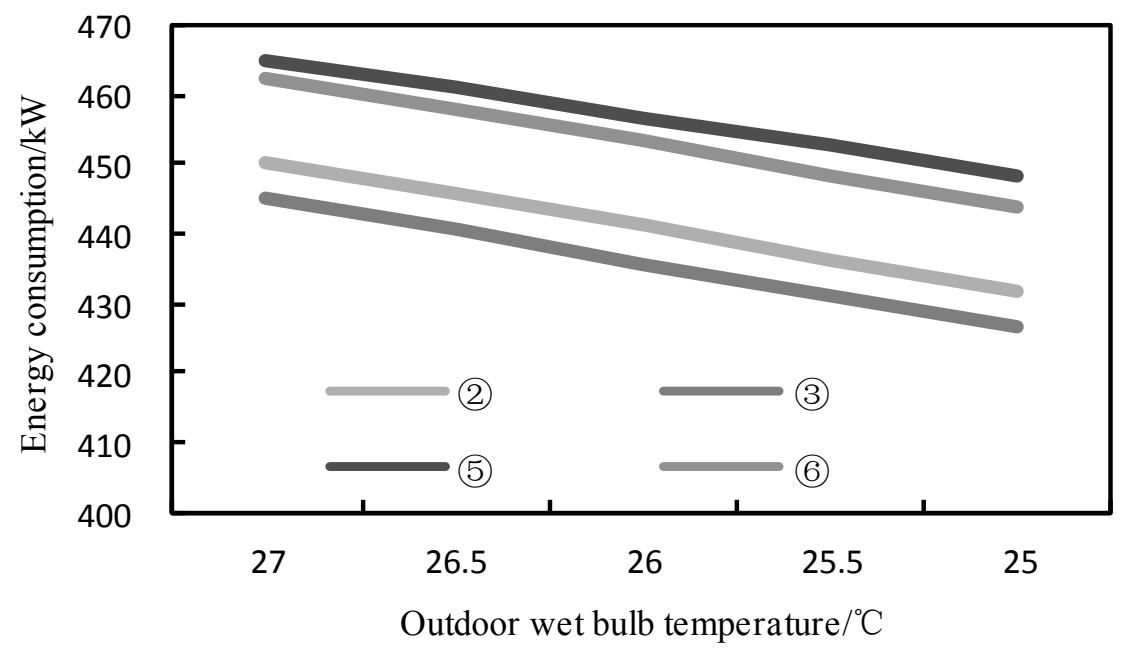

Fig. (3). Energy consumption of different controlling mode under $80 \%$ load rate. 


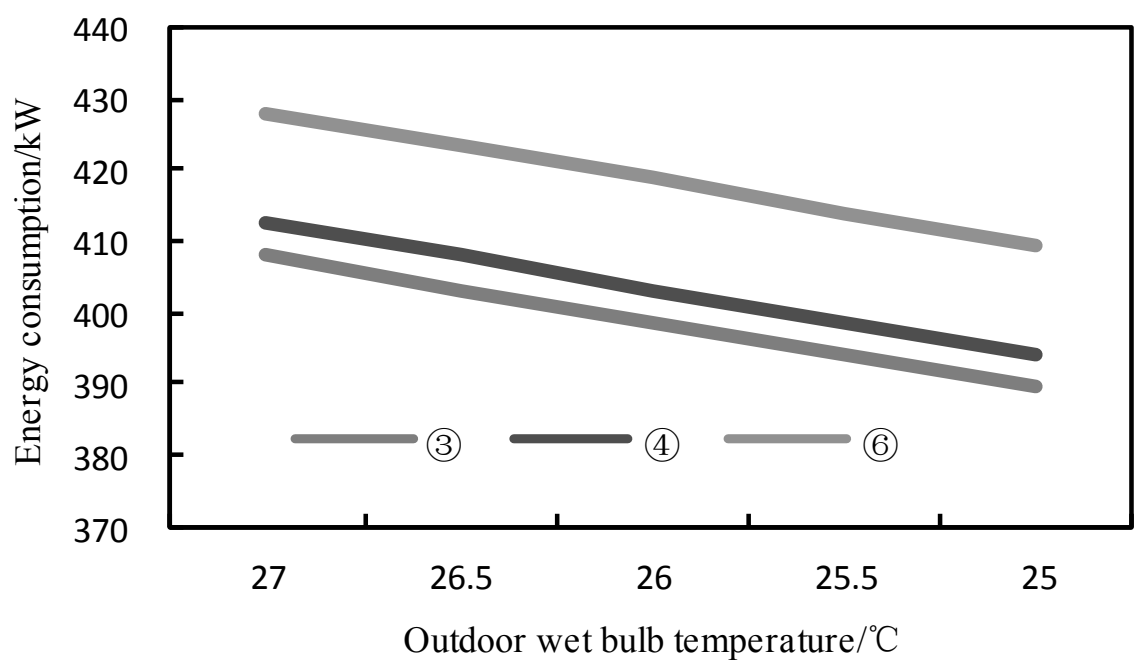

Fig. (4). Energy consumption of different controlling mode under $70 \%$ load rate.

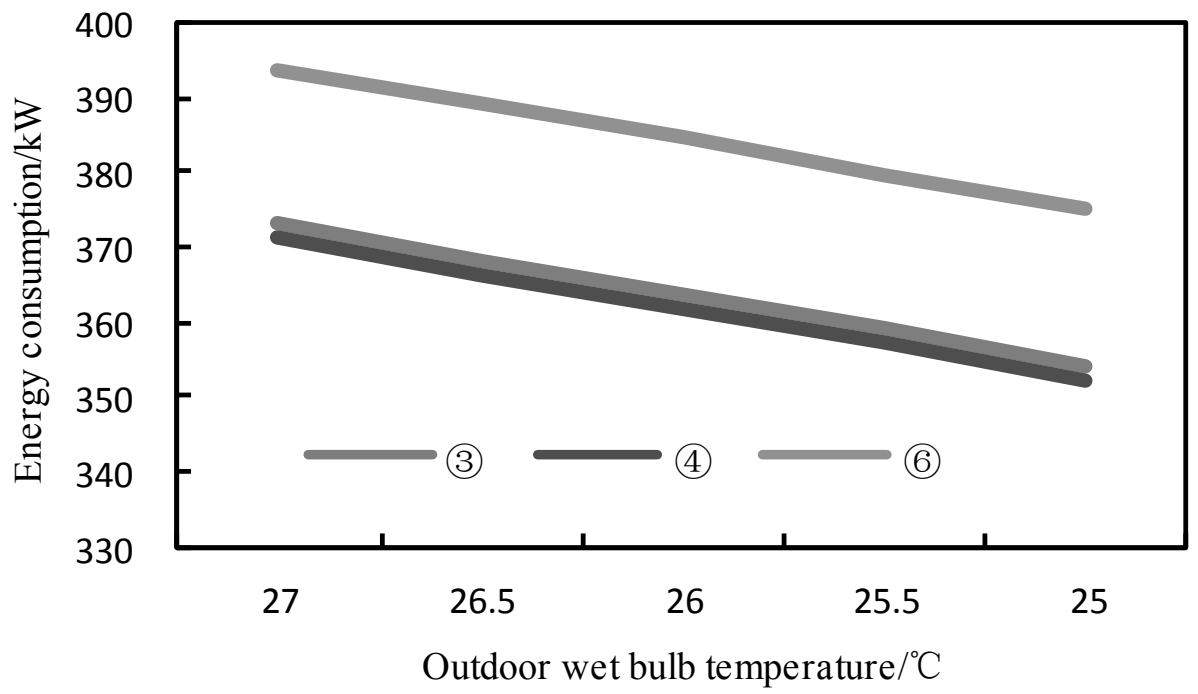

Fig. (5). Energy consumption of different controlling mode under $60 \%$ load rate.

Running two cooling towers at the same time is required, owning to heat exchange capability limit of a single tower. This is a common operation strategy but not an energy efficient one.

It's worth noting that the corresponding optimum temperature difference of cooling water decreases with load rate under partial load conditions. The optimum operation mode for cooling water pump is at a constant flow control while the flow for the cooling tower fan has variable frequency control. In practice, variable frequency control for pumps may reduce system energy consumption because the decrease of water flow lowers the energy efficiency of chillers, which is uneconomical for the cooling water system. Therefore, energy efficient operation for cooling water system needs to be formulized through variable frequency control of cooling tower fan as the influence of water flow change on chiller performance is greater than that of the water temperature.

Under partial load rate condition, the optimum operation mode of cooling water system is optimal $t_{\text {out }}$ control which aims at the lowest comprehensive system energy consumption. This operation mode may let cooling water system match the optimal temperature difference and determine the fan frequency according to optimum outlet temperature automatically. Optimum temperature difference decreases with the reduction of load rate. The system reaches its optimum operating condition when the pump flows at $537 \mathrm{~m}^{3} / \mathrm{h}$. As the flow of the pump selected for this teaching building is $700 \mathrm{~m}^{3} / \mathrm{h}$ which is bigger than normal, the optimal operation condition may be obtained by variable frequency control or by replacing the existing pump. 


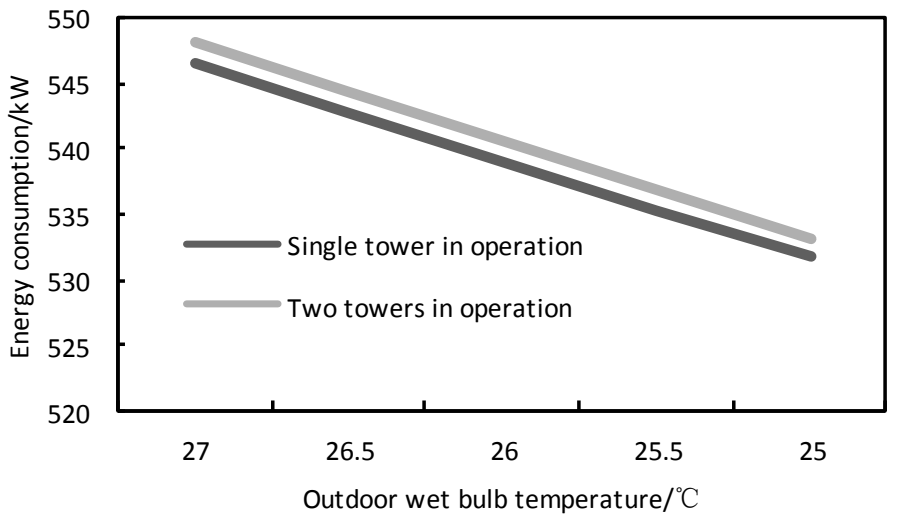

Fig. (6). Energy consumption when different number of cooling tower in operation under $100 \%$ load rate.

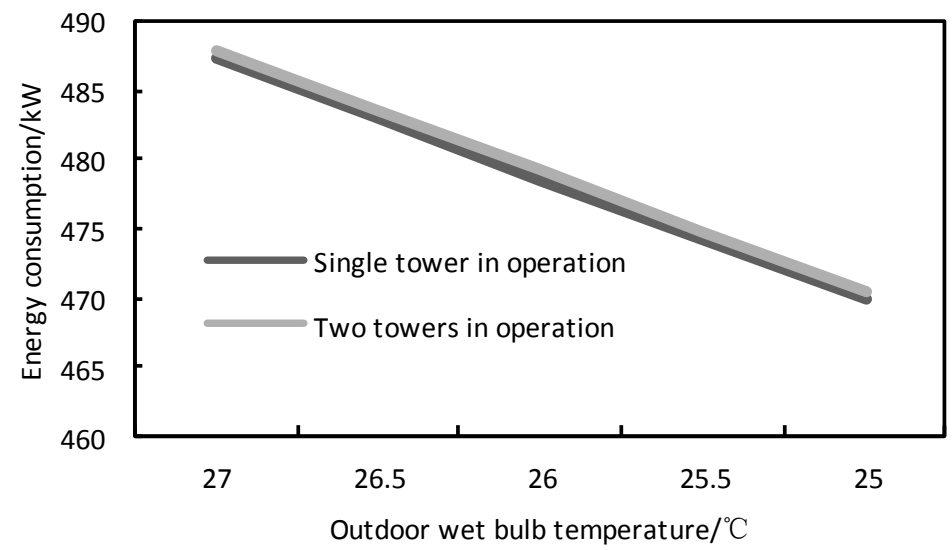

Fig. (7). Energy consumption when different number of cooling tower in operation under $90 \%$ load rate.

\section{OPTIMUM CONTROL STRATEGY FOR TWO TOWERS IN SERVICE SIMULTANEOUSLY}

When there are several towers in one cooling water system, the operation mode maybe a tower-one chiller-one pump or multi-tower-one chiller-one pump. When several towers are running at the same time, higher energy efficiency and lower energy consumption of chiller can be obtained because of lower $t_{\text {out }}$ although the energy consumption of the fan increases.

Suppose that two towers are running at the same time, water flow of each tower is half of that only one in operation under same $t_{\text {in }}$ and thermodynamic property of the towers.

Under these two operational modes mentioned above the optimum $t_{\text {out }}$ has been obtained by the use of constrained nonlinear unary optimization method with MATLAB software when cooling water temperature difference at $4^{\circ} \mathrm{C}$. The calculated results of energy consumption for cooling water system at different load rate and different $t_{s}$ are as shown in Figs. (6-10).

There is little difference between system energy consumption when single tower or two towers are in operation when $t_{s}$ decreases from $27^{\circ} \mathrm{C}$ to $25^{\circ} \mathrm{C}$ under different load rates. The reason is that when a single tower is in service, the reduction of energy consumption of fan is much less than that of the chiller, moreover the energy efficiency of the chiller may also be lowered in single tower condition. The difference is within $0.31 \%$ at different $t_{s}$ under different load rate [16].

Measured data shows that the water concentrated in some areas in the filling layer is not distributed evenly, owing to dirt within the tower, which lessens the air to water ratio, and then the heat exchange area cannot be used effectively. It can be shown from the correlation regression expression of $t_{\text {out }}$ statistical model for this tower that the influence of air flow is the lowest. After cleaning and maintenance of the cooling tower, the correlative coefficient in this statistical model may increase while the influence of numbers in operation on energy consumption of cooling water system may decrease or even there will be energy saving. The system may operate efficiently through variable frequency control for fan as cooling water temperature plays less influence on the chiller's efficiency. The heat exchange area can be used effectively when several towers are running simultaneously and at this time the lowest energy consumption of system is dependent on the air flow. Therefore, better maintenance must be needed for an even distribution of water and effective use of tower's heat exchange area in order 


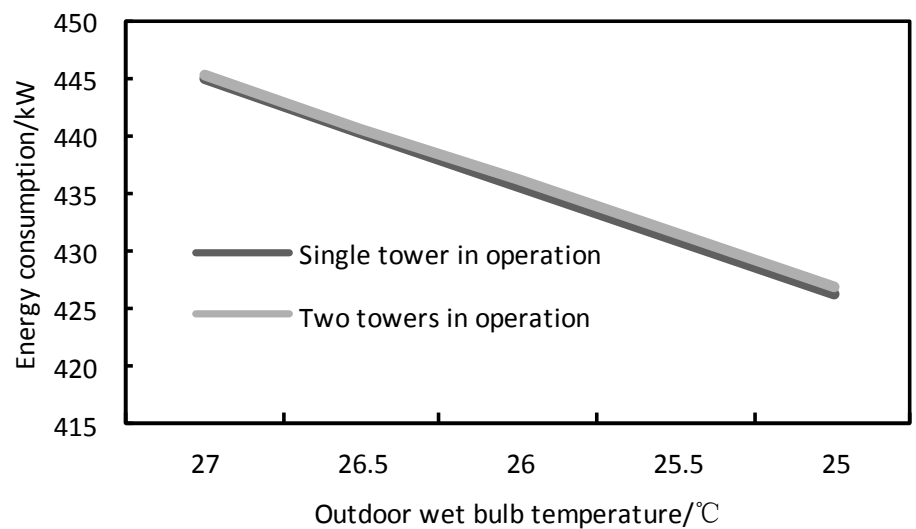

Fig. (8). Energy consumption when different number of cooling tower in operation under $80 \%$ load rate.

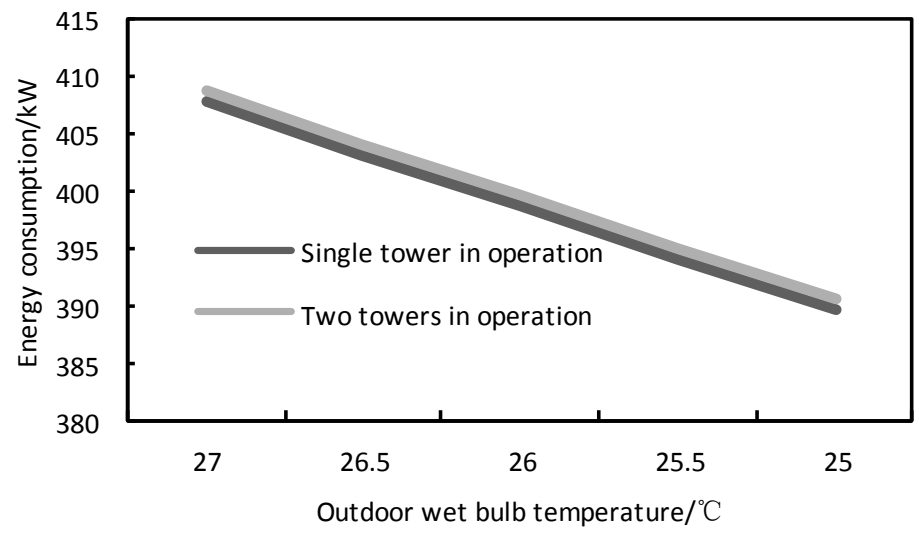

Fig. (9). Energy consumption when different number of cooling tower in operation under $70 \%$ load rate.

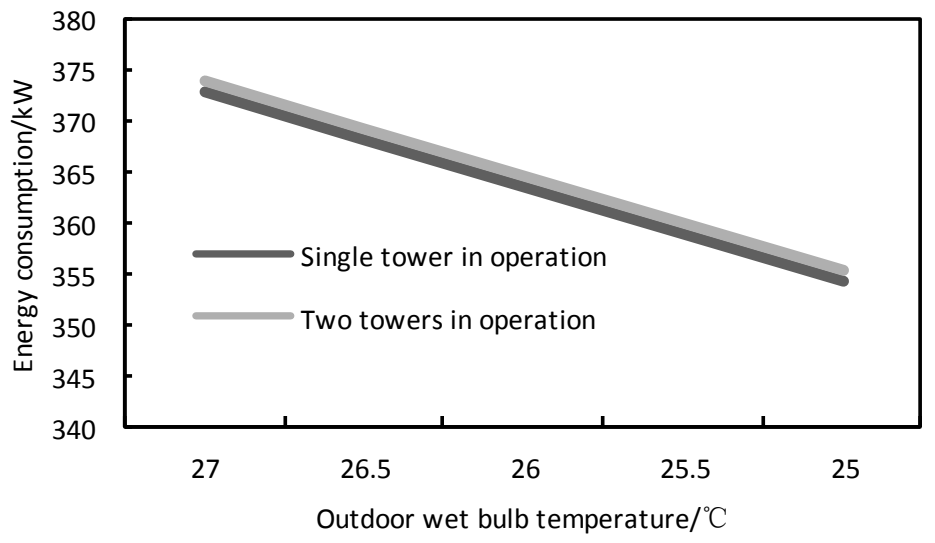

Fig. (10). Energy consumption when different number of cooling tower in operation under $60 \%$ load rate.

toacquire higher energy efficiency of the cooling water system under less air flow and the same cooling effect. Synchronous frequency control has been widely used for the energy efficiency of tower fans [8].

\section{CONCLUSION}

1) Through correlation analysis of the factors influencing cooling tower and study on coupling model of chiller, pump and tower, it is shown that in partial load conditions the best operation mode of cooling water system is the optimal outlet water temperature control mode, which aims at the lowest comprehensive system energy consumption. Thus, cooling water system can match the best temperature difference and determine the fan frequency according to optimum outlet temperature automatically. When the pump selected for the system is bigger than normal, the optimal operation condition may be obtained by variable frequency control or by replacing the existing pump with a smaller one. 
2) Several cooling towers should be in operation simultaneously as the water temperature variation has a lower impact on chiller's energy efficiency than water flow. Variable frequency control should be applied to fans meanwhile routing maintenance and cleaning is also needed in order to maintain an even distribution of water and effective use of heat exchange area.

\section{CONFLICT OF INTEREST}

The authors confirm that this article content has no conflict of interest.

\section{ACKNOWLEDGEMENTS}

Financial contributions to this study is Project (13zx7110) supported by Research Foundation for PHD of Southwest University of Science and Technology.

\section{REFERENCES}

[1] J. Zhou, W. Chen, and R. J. Chen, "Operation management and energy saving of cooling tower in central air conditioning systems," Heating Ventilating \& Air Conditioning, vol. 40, no. 4, pp. 110$114,2010$.

[2] K. Qu, and D. Hu, "Optimal energy saving control strategy for cooling water system in air conditioning systems," Heating Ventilating \& Air Conditioning, vol. 40, no. 4, pp. 110-114, 2010.

[3] S. Di, "Energy efficiency of cooling towers in air conditioning systems," Heating Ventilating \& Air Conditioning, vol. 29, no. 6, pp. 33-34, 1999.
[4] D. E. Thielman, "Chiller optimization by energy management control system," ASHRAE Journal, vol. 25, no. 1, pp. 60-62, 1983.

[5] R. T. Olson, and J. S. Llebman, "Optimization of a chilled water plant using sequential quadratic programming," Engineering Optimization, vol. 15, no. 3, pp. 171-191, 1990.

[6] S. B. Austin, "Chilled water system optimization.," ASHRAE Journal, vol. 35, no. 7, pp. 50-56, 1993.

[7] Y. Yao, Z. Lian, Z. Hou, and X. Zhou, "Optimal operation of a large cooling system based on an empirical model," Applied Thermal Engineering, vol. 24, no. 16, pp. 2301-2321, 2004.

[8] J.E. Braun, S. A. Klein, and J.W. Mitchell, "Effectiveness models for cooling towers and cooling coils," ASHRAE Transactions, vol. 95, no. 2, pp. 164-174, 1989.

[9] M. A. Bernier, "Cooling tower performance: theory and experiments," ASHRAE Transactions, vol. 100, no. 2, pp. 114-121, 1994.

[10] M. A. Bernier, "Thermal performance of cooling towers," ASHRAE Journal, vol. 37, no. 4, pp. 56-61, 1995.

[11] S. Mick, "Take it to the limit or just halfway," ASHRAE Journal, vol. 40, no. 7, pp. 32-39, 1998.

[12] M. S. Soylemez, "Theoretical and experimental analyses of cooling towers," ASHRAE Transactions, vol. 105, no. 1, pp. 330-7, 1999.

[13] A. Hasan, and K. Sire'n, "Theoretical and computational analysis of closed wet cooling towers and its applications in cooling of buildings," Energy Build, no. 34, pp. 477-86, 2002.

[14] A. Kloppers, and G. Kro"ger, "Cooling tower performance evaluation: Merkel, Poppe, and e-NTU methods of analysis," Journal of Engineering for Gas Turbines and Power, no. 127, pp. 1-7, 2005.

[15] ASHRAE, "HVAC 1toolkit: a toolkit for primary HVAC system energy calculation," American Society of Heating, Refrigerating, and Air-Conditioning Engineers, 1999.

[16] L. Wang, J. Lu, and X. Wang, "Optimal operation method of cooling towers of air conditioning system," Heating Ventilating \& Air Conditioning, vol. 41, no. 7, pp. 141-144, 2012.

Received: October 16, 2014

Revised: December 23, 2014

Accepted: December 31, 2014

(C) Liang et al.; Licensee Bentham Open.

This is an open access article licensed under the terms of the Creative Commons Attribution Non-Commercial License (http://creativecommons.org/licenses/by$\mathrm{nc} / 4.0 /$ ) which permits unrestricted, non-commercial use, distribution and reproduction in any medium, provided the work is properly cited. 